\title{
EDITORIAL
}

\section{The case for inclusion: mental health and the NSF for long-term conditions}

\author{
Annie Lau
}

The 'long-term conditions' model of care was originally conceived by the Kaiser Permanente healthcare organisation in the USA. It involves stratification of the level of risk of populations in the community who have chronic conditions. Teams are formed with both primary and secondary care staff to provide personalised outreach services to identified vulnerable individuals before a crisisdriven hospital admission becomes necessary. These teams, led by community matrons, work across organisational boundaries. The primary objective, and the major criterion of success, is reduction of admissions to acute hospital beds. Patients are empowered and helped to better manage independent living in the community. This involves redesign of existing care pathways and outcome measures. Case management models such as the UK Evercare pilots for care of the elderly (Boaden et al, 2005) are being introduced and evaluated in a number of localities.

Early work by Chris Dowse (e.g. Dowse, 2003) and a report from the King's Fund reviewing lessons from chronic disease management in the USA (King's Fund, 2003) were followed by the formation and launch in 2004 of 'long-term conditions learning collaboratives', under the aegis of strategic health authorities.

\section{The NSF for Long-Term Conditions}

The National Service Framework (NSF) for LongTerm Conditions (Department of Health, 2005a) is a 10 -year programme for change. Its focus is on longterm neurological conditions such as multiple sclerosis, although the Minister of State for Health
Box 1 The quality requirements of the NSF for Long-Term Conditions

1 A person-centred service

2 Early recognition, prompt diagnosis and treatment

3 Emergency and acute management

4 Early and specialist rehabilitation

5 Community rehabilitation and support

6 Vocational rehabilitation

7 Providing equipment and accommodation

8 Providing personal care and support

9 Palliative care

10 Supporting family and carers

11 Caring for people with neurological conditions in hospital or other health and social care settings

(Department of Health, 2005a)

notes that many of its 11 quality requirements (Box 1) apply equally to people with other long-term conditions, disabilities or persistent pain (Department of Health, 2005a: p. 1).

In line with the long-term conditions model of care, the purpose of this NSF is to transform health and social care services to improve the quality of life of people with chronic conditions and support their independent living.

\section{Relevance for mental health}

Practising clinicians know that many mental health disorders are as lifelong and enduring as diabetes and asthma. Each year eight billion pounds are spent by the National Health Service (NHS) and social

Annie Lau is a consultant psychiatrist and Senior Medical Advisor, Patient Safety, with North East London Mental Health NHS Trust (Goodmayes Hospital, 157 Barley Lane, Ilford IG3 8XJ, UK. E-mail: annie.lau@djpconsulting.co.uk). She was formerly Medical Director (April 2001 to March 2005), and the ideas in this article were developed together with colleagues in the Long Term Conditions Collaborative, North East London Strategic Health Authority. This discussion reflects her interest in promoting coherent patient-centred care pathways across health and social care organisations, and putting mental health services in the mainstream of health services development. 
services on mental illness (Layard, 2004). According to the Psychiatric Morbidity Survey (Singleton et al, 2001), $16 \%$ of adults of working age have a mental illness, and up to a half of these people are seriously ill. Suicide is the second most common cause of death among young people in England (Dowse, 2003).

There is obviously a clear case for inclusion, and prioritisation, of mental health in the government's programme of reform of health services provision. However, mental health is omitted from the next step in NHS reforms, the Long-term conditions agenda (Department of Health 2005b), as has been pointed out by the NHS Confederation in its briefing paper on long-term conditions (NHS Confederation, 2005). What are the relevance and implications of this policy for mental health services in the UK? Chronic physical conditions are clearly its focus, and longterm mental illness is barely mentioned.

Although the major psychoses more obviously fit the long-term conditions paradigm, other mental health disorders, for example, obsessive-compulsive disorder, chronic depression and a number of comorbid conditions such as personality disorder with substance misuse, can be as crippling, causing long-term disability and affecting quality of life. Better management across the primary and secondary services divide can contribute significantly to suicide prevention and risk management. In the UK, secondary services in adult mental health concentrate almost exclusively on serious mental illness, often because of reduced resources and increasing demand together with problems caused by rising comorbid substance misuse. As a result, primary care practitioners struggle with 'heart-sink' patients, many with chronic depression or personality disorder, both of which contribute significantly to suicide risk in the community.

\section{Links between mental health and physical conditions}

\section{Chronic illness}

Mental health also plays an important part in the management of treatment adherence in many longterm physical conditions. Furthermore, in mental illness unwanted side-effects of psychotropic medication contribute to physical morbidity. The metabolic syndrome of weight gain, glucose intolerance, insulin resistance and hypertension associated with antipsychotics, for example, is highly predictive of type 2 diabetes and cardiovascular disease. Obesity is common in patients in long-stay psychiatric environments, including high secure units, where they are exposed to high-calorie diets with insufficient opportunity to exercise. We know that schizophrenia is an independent risk factor for heart disease.

\section{Liaison services}

The experience of psychiatric liaison services in acute hospitals also informs us that effective management of treatment adherence for many longterm physical conditions involves joint care plans with both physical and mental health input. With elderly people, prevention of falls is an important part of the management of long-term physical conditions in acute old age wards; but it is important also to realise that many of these individuals also have depression or early dementia, which may not be recognised and given proper treatment.

This is also an opportunity to remind ourselves that a key recommendation of the inquiry into the death of Daksha Emson, a doctor who killed herself and her child, was that joint care plans be organised with both mental health and obstetric services for mothers at risk of severe postnatal depression (North East London Strategic Health Authority, 2003). What would be the findings of a nationwide survey of compliance with this important directive?

A renewed focus on the links between mental health and physical conditions across the age range, through modifications of the principles of the longterm conditions model of care, would enable more holistic services to be developed and better health and social care to be offered to patients. It also is an opportunity to tackle stigma and the common avoidance of issues surrounding mental illness by policy-makers.

\section{Development of competencies in primary care}

The long-term conditions agenda is also about better services led by primary care, with the support and expertise of secondary care professionals. The aim is to enable primary care services to meet more of the needs of individuals with mental health disorders and to offer them better recovery programmes in the community with engaged primary care practitioners. To achieve this we must review the transitions between primary and secondary services, and redesign care pathways, building outcome evaluations into care programmes. It also requires more outreach activities by secondary services and a breaking down of training barriers, with secondment of primary care practice staff to secondary services.

There is increasing evidence that colleagues in general practice are now ready for new thinking and initiatives involving mental health issues. Mental health registers have been introduced and general practitioners with special interests (GPSIs) are being trained. Recent articles in the $B M J$ have also highlighted patient preference for more mental health 
care to be located with GPs (e.g. Bower \& Gilbody, 2005; Lester et al, 2005). Depression has been cited as a prime target for development of primary care competencies.

\section{Involvement in sector-wide 'long-term conditions collaboratives'}

So what can psychiatrists do? Over the past year, each strategic health authority has set up 'long-term conditions collaboratives' led by primary care trusts to share learning and best practice on the development of pilot projects in the management of longterm conditions. Psychiatrists can get involved with willing GP partners in initiatives that allow more seamless ways of working to be developed - perhaps a modification of the care programme approach, but with more primary care input. This means a challenge to the way services are currently delivered, in terms of organisational structure and type of staff deployed. The results can be a return to a way of working in which the patient experiences a more integrated care pathway and continuity in their journey along it; a new concordat between psychiatrists, primary care practitioners and social services; and much better job satisfaction, and higher morale for psychiatrists and their teams.

\section{References}

Boaden, R. Dusheiko, M., Gravelle, H., et al (2005) Evercare Evaluation Interim Report: Implications for Supporting People with Long-term Conditions. Manchester: National Primary Care Research and Development Centre. http://www. natpact.nhs.uk/uploads/2005_Feb/Evercare_ evaluation_interim_report.pdf

Bower, P. \& Gilbody, S. (2005) Managing common mental health disorders in primary care: conceptual models and evidence base. $B M J, 330,839-842$.

Department of Health (2004) The NHS Improvement Plan: Putting People at the Heart of Public Services. London: Stationery Office.

Department of Health (2005a) National Service Framework for Long-Term Conditions. London: Stationery Office.

Department of Health (2005b) Supporting People with LongTerm Conditions: An NHS and Social Care Model to Support Local Innovation and Integration. London: Stationery Office.

Dowse, C. (2003) Managing Chronic Conditions in the NHS. London: NHS Modernisation Agency.

King's Fund (2003) Managing Chronic Disease - What Can We Learn from the US Experience? London: King's Fund.

Layard, R. (2004) Mental Health: Britain's Biggest Social Problem? London: Department of Health. http://www.strategy.gov.uk/ downloads/files/mh layard.pdf

Lester, H. E., Tritter, J. Q. \& Sorohan, H. (2005) Patients' and health professionals' views on primary care for people with serious mental illness: focus group study. BMJ, 330, 11221126.

NHS Confederation (2005) Briefing: Supporting People with Long-Term Conditions. London: NHS Confederation.

North East London Strategic Health Authority (2003) Report of an Independent Inquiry into the Care \& Treatment of Daksha Emson \& Her Daughter Freya. London: NELSHA. http:// www.nelondon.nhs.uk/documents/de_inquiry_report.pdf

Singleton, N., Bumpstead, R., O'Brien, M., et al (2001) Psychiatric Morbidity Among Adults Living in Private Households, 2000. London: Stationery Office.

\section{Evidence-Based Mental Health}

Need to stay ahead? Evidence-Based Mental Health is a quarterly journal from the Royal College of Psychiatrists, the British Psychological Society and BMJ Publishing Group that provides instant access to high-quality evidence. Adopting a multidisciplinary approach to mental health and linking clinical research to practice, $E B M H$ is a must for mental health practitioners worldwide.

Articles for Evidence-Based Mental Health are selected from over 130 international journals. The criteria used to select these articles are designed to extract the most clinically relevant and scientifically valid papers available.

The articles are summarised and a commentary by a clinical expert added to each one.

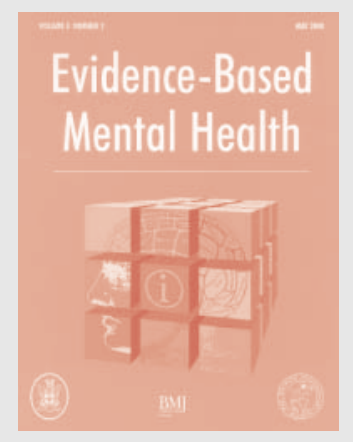

www.ebmentalhealth.com

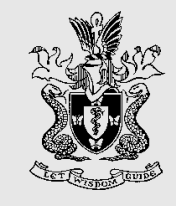

There are discounted rates for:

- First-time subscribers

- Paying by direct debit see: www.ebmentalhealth.com or contact

- RCPsych and BPS Members

For further information and current subscription rates, BMJ subscriptions hotline on +44 (0)20 73836270 . Email: subscriptions@bmjgroup.com 